\title{
ETIOLOGY AND TREATMENT OF PLANTAR ULCERS
}

\author{
"Patients must not walk on wounded feet" \\ W. F. Ross, M.B.B.S., D.T.M. \& H.
}

(This is a report of a talk given at the Schieffelin Leprosy Research Sanatorium, Karigiri P.O.,; Via Katpadi, N.A., Hospital Day 1960.)

"Doctor my feet are killing me" is often the complaint that brings patients with planter ulcers to us. The treatment and prevention of these wounds would be made much easier if it were. As it is plantar ulcers can be prevented and cured in the great majority of cases but only by painstaking application of well understood surgical principles.

\section{The extent of the problem}

HemeriJkx found $9.3 \%$ of 2,479 out-patients at Polambakkam, in S. India had plantar ulcers on one or both feet and the author found a similar proportion, $10 \%$ of out-patients with plantar ulcers in E. Nigeria.

If these can be accepted as indicative of the world incidence of plantar ulcers then, taking the W.H.O. estimate of total incidence of leprosy which is 10 million, we have the alarming figure of 1 million patients with wounded feet.

At Karigiri, between 25 and 30 of regular out-patients have or have had plantar ulcers and of these $50 \%$ are dependent on relatives or society for their support.

The prime difficulty in prevention and treatment of ulcers is to gain the cooperation of the patients. The treatments offered must be acceptable and effective. Many leprosy patients feel that their ulcers are an inevitable concomitant of their disease and their attitude can only be overcome by repeated and careful explanation and by the example of other patients whose feet are ulcer free as a result of treatment.

\section{Etiology and natural history}

This is necessarily a brief review and does not attempt to cover all the possible factors. Ulcers on the sole due to lepromatous leprosy per se are very rare, less than $1 \%$ of the total, and are not considered further.

Plantar ulcers only occur on feet which are both anaesthetic and walking. In addition it seems likely that defective circulation due to 
irreversible changes in blood vessels plays some part (JoB, 1960) and it has been pointed out that fixed deformity is a very important factor in their causation (SFDDON 1960).

For practical purposes these ulcers mav be divided into two groups:

I. First ulcers on virgin feet.

II. Recurrent ulcers on previously damaged feet.

Essentially the etiology of both is the same; but, as is wellknown, once a patient has had an ulcer it is extremely difficult, but not impossible, to prevent a recurrence.

\section{The FirSt UlCer}

(a) Casual Trauma. Some ulcers are caused by casual trauma. By this is meant cuts, burns, thorn wounds, surface friction blisters and injuries due to badly fitting shoes or badly made shoes, e.g. nails sticking into sole. The natural history of such an ulcer is a break in the skin, often quite minor, unnoticed by the patient who continues to walk. The wound becomes infected. There is local oedema and regional lymphadenopathy and the wound, subject to the trauma of walking fails to heal. Recently, I had such a wound myself. I was well aware of it but continued to walk, partly out of curiosity. In 3 weeks it did not heal despite daily dressing and at the end of the time I had painful glands in the groin and a very sore foot. Then I was confined to bed for three days by fever, and the wound healed.

"Patient must not walk on wounded feet".

(b) Plantar Warts. Occasionally, ulcers occur under plantar warts and they are sometimes seen after unskilled cutting for corns or careless removal of callosities.

(c) Cracks. Another relatively uncommon cause of ulceration is the infected crack. Many barefooted people have dry feet and when the hardening effect of repeated immersion in water followed by rapid drying in the hot sun is added to anhydrosis and skin atrophy due to nerve involvement, then the soles become very dry and hard indeed. Such soles are prone to cracks. Deep cracks may extend to the subcutis and provide an opening for bacilli and the beginning of an ulcer. These cracks are commonly found at the lateral margins of the heel and at the flexor creases in the forefoot. (Figure 1.) Tiny hairline cracks are also found on the weight bearing surfaces, particularly in patients who wear hard leather chappals whose feet are polished like patent leather. The cracks may be alleviated by regular oiling of the feet and prevented from becoming deep by means of rigid sole footwear.

(d) Subcutaneous Necrosis. We find that these three factors, casual trauma, plantar warts, and infected cracks account for only a small 


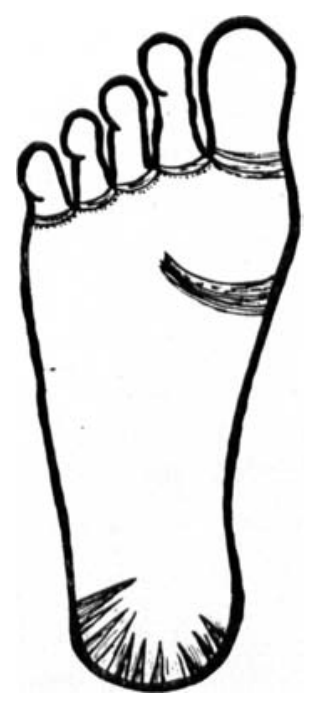

\section{FIG. I. TO SHOW THE COMMON} SITES OF DEEP CRACKS IN ANAESTHETIC FEET.

proportion of sole wounds. These three show, first a break in the skin, then bacterial invasion and then a septic superficial ulcer which will, unless localised, cause spreading inflammation. But the true and common plantar ulcer begins as a deep necrosis, often at its first appearance penetrating from the skin to plantar fascia or tendon sheath.

(1) The pre-ulcer. The first stage of such an ulcer is an aseptic inflammation of subcutaneous tissue which manifests itself in three ways.

(i) Tenderness over the affected zone. Despite the fact, that all these ulcers occur in feet with some sensory deficiency, deep pressure sensation at the metatarsel heads is rarely lost and deep tenderness is a reliable early sign of inflammation (PRICE, 1959).

(ii) Swelling of the tissues and slight spreading of the toes. There is localised oedema resulting in the toes adjacent to the affected zone being forced apart.

(iii) Often there is visible in the subcutis a small, uninfected haematoma. Ulcers are rarely seen at this stage in outpatient work but they can be picked up at a resident institution, particularly where patients' feet are regularly examined. If a patient with tenderness, swelling and subcuticular haematoma on the foot is put to 
bed for a few days, the whole thing subsides. If he continues to walk the second stage of ulceration ensues. This is necrosis of the zone of inflammation.

(2) Subcutaneous Necrosis. In the first place this necrosis is aseptic and even at this stage if the patient is put to bed, healing will take place.

(3) The Open Ulcer. The third stage is rupture of the haematoma following which infection supervenes. The necrotic tissue is liquefied and in a few days the typical punched-out deep plantar wound penetrating from skin to underlying fascia or tendon sheath develops. These ulcers essentially develop from within outwards. Skin break and infection are late complications.

\section{Etiology}

How can their development be accounted for? It should be noted that these ulcers occur only on feet that are both anaesthetic and walking. There are two possible explanations.

First, that the ulcer is due to pressure leading to ischaemia and localised gangrene of tissue while weight-bearing on an anaesthetic foot. If this was so, we would expect the distribution of wounds to correspond to the distribution of weight in the standing foot, for during walking weight is only borne on any one part of each foot for one eighth of a second or less which is nothing like enough time to give ischaemia sufficient lead to gangrene. But the distribution of ulcers does not correspond to the distribution of weight on the standing foot.

The second possibility is that friction forces set up within the foot (Figure 2a) during walking lead to mechanical damage to the tissues and eventually necrosis and ulceration.

If this is the case we would expect the distribution of ulcers to correspond to the distribution of friction forces in the foot whilst walking. It will be seen from the figures that this is in fact what has been found (Figures $2 b$ and $2 c$ ).

The relationship between forces acting on the foot during walking was hinted at by BRAND and FRITSCHI in 1957 and clearly demonstrated by PRICE in Nigeria in 1958. Observations made at Karigiri agree with Price's finding and although our demonstrations at Karigiri show that most ulcers occur not under hut in front of the metatarsel heads.

(Figure 3.) This confirms the theory of causation put forward by Price. BarnetT (1956) divides the period during which the foot is partially or wholly in contact with the ground in walking, about three-quarters of a second for each step, into 5 phases, which together constitute the walking roll. 

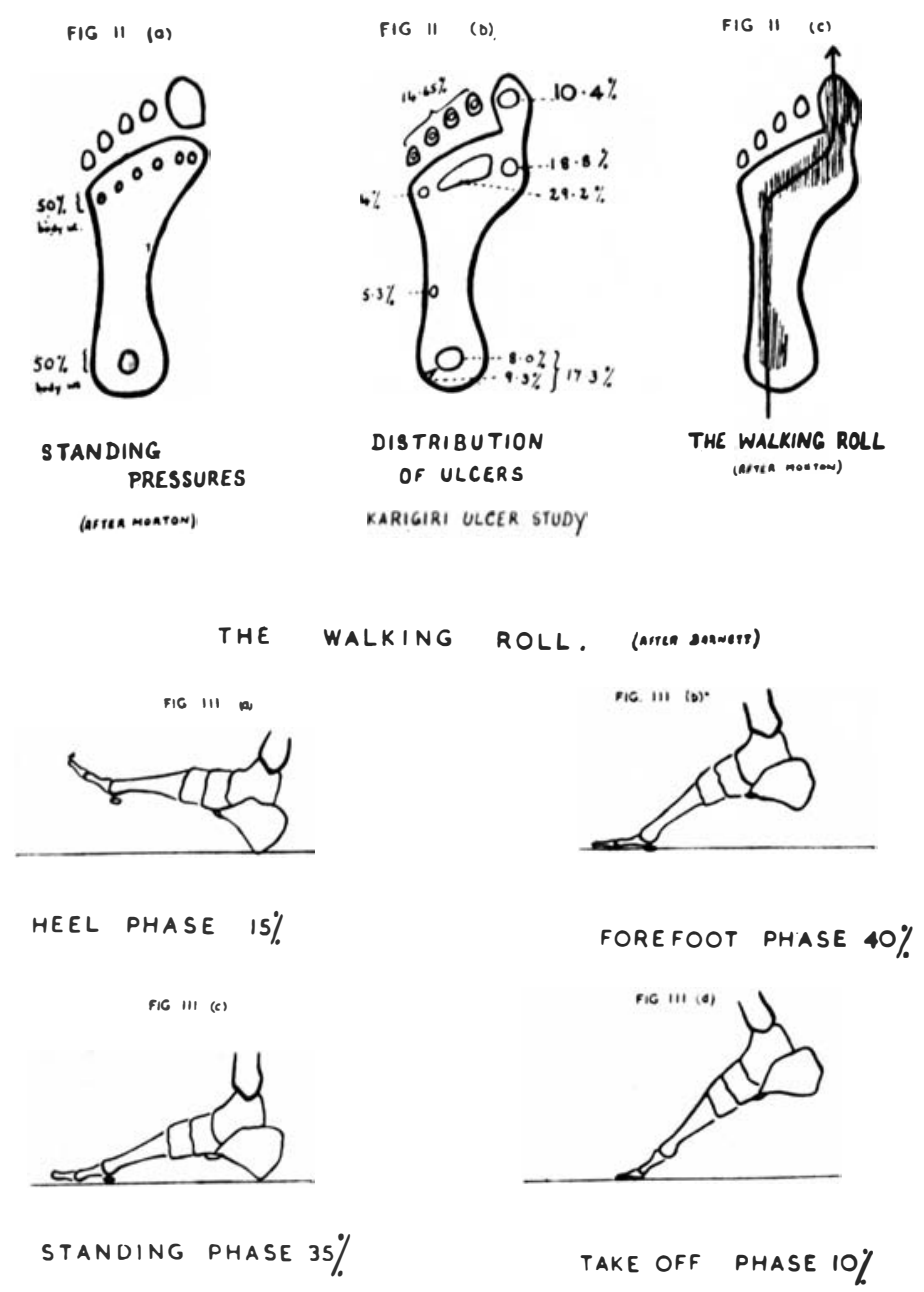

1. The roll begins with the impact of the posterior lateral aspect of the heel on the ground quickly followed by the complete heel. This phase occupies 15 to $20 \%$ of the cycle (Figure 3a).

2. It is followed by the standing phase in which the heel, outer side of sole and the metatarsel head are in contact with the ground. This phase couples 30 to $35 \%$ of the total roll and during it the distribution of pressure is much the same as during standing.

3. During the third or metatarsal heel phase which occupies $10 \%$ of the roll, the weight is borne only on the metatarsal heads, the heel rising from the ground and extension taking place at the metatarse phalangeal (m.p.) phase is occasionally absent as a separate phase. 
4. The fourth or fore-foot phase follows. Thrust is borne on the metatarsal heads and the toes, the hallux and 2 nd toe predominating. The heel continues to rise and further extension occurs at the m.p. joints. The metatarsal heads will rotate through as much as 40 degrees and as the skin is fixed to the ground this rotation is absorbed in the tissues between skin and m.p. joints. It is during this phase that maximum forward thrust occurs, resulting in compression forces behind the metacarpal heads, and shearing forces beneath them and tension in front (Figure 3c).

5. The final step-off phase occupies 3 to $10 \%$ of the roll. Thrust is borne entirely by the toes, the main part of it by the hallux (Figure 3d).

The forces just described act at every step in normal feet as well as in anaesthetic feet. In normal feet, no change is done. In anaesthetic feet, proprioceptive reflexes which normally adjust the pressure put on the foot to the minimum necessary to prevent slipping during walking are out of action. The result is that at each and every step maximum force is exerted on the foot particularly at heel impact and forefoot thrust and the tissues are damaged through sheer overwork. It will be seen that, if as is believed, most plantar ulcers are due to forces acting within the foot and that the most damaging ones act on heel impact and m.p. extension during the thrust of forefoot and metatarsal phase, then a high proportion of these ulcers can be prevented by cushioning heel impact and by reducing or eliminating rotation at the m.p. joints. This can be done by means of rigid sole shoes with microcellular rubber insoles, which will be described in a further section.

There is another factor in the etiology of these wounds which should be mentioned because of its bearing on prevention and treatment, i.e. 'the effect of paralysis.

1. Drop foot due to various degree of lateral popliteal paralysis. The patient walks with a high stepping gait and the foot slaps on to the ground with the whole lateral border. This frequently results in ulceration at the head and the base of the 5th metatarsal.

2. Claw toes due to intrinsic paralysis. The effect of clawing of the toes is threefold. (i) Tissues under the metatarsal heads are put on the stretch. (ii) The toes no longer play their part in walking and all take-off thrust is borne by the metatarsal heads, BARNETT (1956).

3. The arch is raised and the metatarsal heads are relatively lowered, Hicks (1954) (Figure 4). If this process proceeds equally in all five toes then no damage may be done but if one toe is a little more clawed than its neighbour then the associated metacarpal head is pushed down below the adjacent heads and bears an increased proportion of the take-off thrust. The treatment for such 


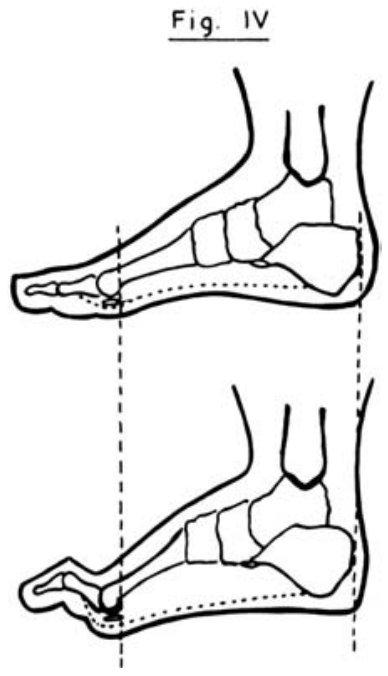

CLAW TOES. WINDLASS EFFECT

\section{ARCH RAISED \& FOOT SHORTENED}

AFTER HICKS. $\varepsilon$.

protruding metatarsal heads is not to trim them, as some recommend, but to correct the clawing and restore the metatarsal head to its normal position in line with its fellows, BRAND and FritsCHI (1957).

\section{I. Recurrent Ulcers on Previously Damaged Feet}

In addition to anaesthesia the foot with healed ulceration may display the following defects.

(a) Scarring and loss of friction reducing mechanism. (b) Necrosis blister. (c) Fixed deformity (SEDDon, 1960). (d) Discreet cysts of purulent material.

(a) Scarring and loss of friction reducing mechanisms. Scar tissues being rigid and having poor blood supply, is much less able to withstand the stress forces set up in the heel and forefoot during walking than normal tissue. If in addition to scarring the smooth cartilaginous surface of the normal metatarsal head has been destroyed, the already abnormal tissues are literally ground between the rough metatarsal head and the walking surface. It is not surprising that such feet will re-ulcerate after as little as 15 minutes of walking. Callosities and hyperkeratotic scars are common findings. These are often as hard as stones and must be removed, or fresh wounds will result. 
(b) Necrosis blisters. This is a subcuticular collection of tissue fluid with black necrotic debris floating in it which is usually sterile. It usually appears as a blister at the margin of the foot where the thick volar skin meets the thin dorsal skin. These blisters are commonly attributed to burns. They are not burns. The fluid has tracked under the plantar skin from a deep-seated sterile necrosis at the site of a previous ulcer. If the blister is left untouched, and the patient put to bed, it will dry up without further trouble.

If the patient continues to walk, the blister ruptures, infection supervenes and an infected wound results.

(c) Fixed deformity. In patients with sciatic nerve lesions SEDDon found that "loss of sensibility of the sole is far less important than the fixed deformity" in the causation of persistent ulceration.

Fixed deformation or deformities do not appear to play such an important part in the causation of ulceration in leprosy patients, but SEDDON's statement serves to underline the difficulties that ensue when secondary fixed deformities are allowed to develop, and the extreme importance of detecting the pre-ulcer and thus preventing the bone and joint infection that so commonly leads to fixed deformity.

(d) Intermetacarpal abscess. It has been pointed out, KULONSKI and OERIMAN (1936), that small cysts containing pathogenic organisms are commonly present in anaesthetic feet which have at one time or another had plantar ulcers. These small abscesses may at any time flare up and give acute septic inflammation in the tissues of the foot. The nidus of infection may be in the bone, particularly metacarpals or calcaneum, in cartilage or tendon or in subcutaneous tissue. It may contain a small foreign material such as a thorn or a piece of dressing or it may simply contain purulent material and bacteria. The factors which cause such a cyst to become active after as much as 9 years, as was the case of one patient known to me, are not known but the clinical picture is clear. The patient presents a hot, swollen, painful foot, with lymphadenitis. The treatment is strict bed rest, drainage of the abscess if it can be located and adminis. tration of antibiotics.

\section{Treatment}

1. Curative. The principles of treatment of infected wounds have been known for a very long time; probably the greatest exponents in recent years have been WINNET ORR and TRUETTA and the following notes are based on TRUETTA's classic work, "The principles and practice of War surgery", 1944. The treatment advocated may be summarised as follows:

1. Clean the wound.

2. Excise dead tissues. 
3. Allow free drainage.

4. Immobilize the part.

5. Prevent secondary infection.

6. Stop reception of the trauma causing the wound.

"Patients must not walk on Wounded Feet".

Let us see how these principles apply to three different types of ulcers.

\section{The Violently Affected Wound)}

These are found in association with hot swollen feet, with inguinal adenitis and with copious discharge from the wound.

1. Clean the wound. This may best be done with warm water and soap.

2. Excise dead tissue. Anything obviously dead should be cut away, the object being to remove all slough, without drawing blood. In addition the fibrous scars often seen at the edge of these wounds should be cut away to allow the epithelium to grow.

3. Allow free drainage. Drainage is usually adequate after the dead tissue has been excised, but if not then further incisions and, if necessary, excisions of healthy tissue, must be made until the wound is in no danger of becoming an abscess.

4. Immobilize the part. These limbs should be encased in a light non-weight bearing plaster of paris cast (p.o.p.). They are not suitable for ambulant treatment with p.o.p. The excised wound should be packed, with sterile vaseline gauze or gauze soaked in flavin and paraffin and the p.o.p. applied. In the case of really stinking wounds, filling the wound with $2 \%$ soap solution and then packing with gauze also soaked in soap solution materially reduces the smell.

5. Prevent cross infection. The commonest vehicles of cross-infection are doctors, nurses, orderlies and the patient himself. All these agents may be prevented from adding infection to the wound by encasing it in plaster of paris cast.

6. Stop repeating the trauma. The p.o.p. cast obviously entirely cuts out the walking roll which is the underlying cause of most of these ulcers.

Such a regime will heal any ulcer, no matter how big or badly infected. If the wound is really purulent, after a few days, discharge will begin to show through the plaster. Provided that the patient's condition is satisfactory, i.e. his temperature is normal and lymphadenitis subsiding, the smell may be ignored. The smell from a healing purulent ulcer is quite characteristic and may be confidently described as a "laudable odour". If the discharge has not ceased and 
the smell subsided in two to three weeks after the application of the plaster, then the plaster should be removed under aseptic conditions and the wound re-examined. It will usually be found either the drainage is inadequate or that a previously undetected sequestrum is present.

\section{The Clean Dry Ulcer}

These ulcers show no oedema of the foot, no inguinal adenitis and little or no discharge. They may be treated along the same lines but bed rest is not necessary and they can be sent home in a weightbearing plaster of paris cast, or "Karigiri Boot" (Figure 6). See Appendix 1 for details of the "Karigiri Boot". We find that 6 weeks is a reasonable time to expect p.o.p. casts to remain intact. Proprietary brands of p.o.p. will last longer and some patients, particularly in wet weather, will break up any type of plaster in much less than 6 weeks. If finances allow, glassona, which is a plastic type of cast developed by Messrs. Smith \& Nephew, may be used. It is very tough and water repellent, and will last indefinitely. The "Karigiri Boots" will last 8-12 weeks. We find that these clean, dry ulcers heal at the rate of approximately $0.25 \mathrm{cms}$. per week. This is about half the rate of growth of epithelium under optimum conditions. Unless the patient is prepared to go home to strict bed rest we advise this type of treatment for practically all dry plantar ulcers, however small.

\section{The Mildly Infected Ulcers}

These patients show minimal discharge slight oedema of the foot and little or no inguinal adenopathy. They are not suitable for immediate application of weight-bearing p.o.p. or "Karigiri Boot". We admit these patients to the ulcer ward for treatment, designed to convert these ulcer's into dry, relatively uninfected ones.

1. Cleanse the wound with daily soap and water soaks.

2. Excise dead tissue.

3. Provide drainage.

\section{IMMOBILISE THE PART}

These patients are put on strict bed rest. "Patients must not walk on wounded feet." And after a few days of repeated soaks they are ready for application of weight-bearing p.o.p. or "Karigiri Boot" and discharge.

\section{The Infected CRACK}

The large majority of these cracks will heal satisfactorily in 2 to 4 weeks if the edges are excised, the wound cleaned and then immobilised by strapping a wooden rocker with a felt insole on to the foot by means of elastoplast. This method of immobilisation will 
prevent ulcers from becoming worse but is not a reliable method of treatment except for infected cracks as mentioned above. If a sinus is associated with a crack, then excision to provide free drainage and immobilisation in a weight-bearing p.o.p. cast is essential. There are three further adjuncts to treatment which should be mentioned.

(1) Antibiotics. These are not necessary and their use in in-patient treatment is not recommended because of the chronicity of most of these ulcers and the danger of populating the hospital premises, staff and patients with resistant organisms. If bed space is not available for preparing the mildly infected type of ulcer for p.o.p., then careful cleansing of the wound, excision of dead tissue in outpatients followed by application of felt and a rocker and the administration of $4 \mathrm{cc}$. of a long-acting penicillin is recommended as a practical alternative.

These patients should be asked to report after one week. It may be that careful use of antibiotics after sensitivity testing would reduce the period of hospitalisation needed to prepare infected wounds for weight-bearing casts, but this has yet to be demonstrated.

(2) Preventative surgery. Claw toes and foot drop secondary to paralysis should be corrected preferably by tendon transfer, BRAND and FRITSCHI (1957). Toes which are twisted and rigid, should be removed. The only bone cutting operation which commends itself is the removal of the spur of bone from the underside of the calconeum which is commonly present following an ulcer on the heel, DreisbaCH. The utmost conservatism should be the rule when considering surgery of the metatarsals. If sequestration occurs, remove the sequestrum but normal metatarsal heads should never be removed.

(3) Ascorbic acid. The work of the RAO et al. (1956) has shown that the majority of people in South India are deficient in ascorbic acid. The importance of this vitamin in the healing of wounds has been demonstrated many times and although no controlled study has yet been carried out in the healing of ulcers in leprosy patients, it is recommended that all ulcer patients should receive at least $300 \mathrm{mgm}$. of ascorbic acid daily whilst under treatment, and it would probably be wise to continue to administer the vitamin in lower dosage for a prolonged period.

Appendix 1. The "Karigiri Boot" (Figure 6). This boot has been developed from the shoe described by Brand in an addendum to Chapter XXII of "Leprosy in Theory and Practice", Cochrane, R.G., 1959.

It is cheap, costing approximately $5 /-$, effective, acceptable to the patients and can be applied to outpatients who have to go home the same day. It may be applied to all cases suitable for the application of weight-bearing p.o.p. casts. 


\section{Appendix 2}

Pre-vulcanised rubber latex may be obtained from: The Dunlop Rubber Co., Chemical Products Division, Erdington, Birmingham. Please mention the purpose for which the latex is needed as Dunlops are making a special mix for me. Revertex Ltd., 51/55, Strand, W.C.2. Ask for Mr. Revultex. Rubber Latex Ltd., Harling Road, Wythanshaw, Manchester 22.

\section{Karigiri Boot}

Further experience has shown that a wooden clog may be used to provide the rigid sole for the Karigiri Boot. This can be either made locally or obtained from: Snaith Clog Manufacturing Co., Snaith, Yorkshire. Old nylon stockings are an effective substitute for the cotton socks originally described, and a similar stocking drawn over the outside gives a neat finish to the boot.

$$
\text { fig. } V \text { the "shuffle boaro" }
$$
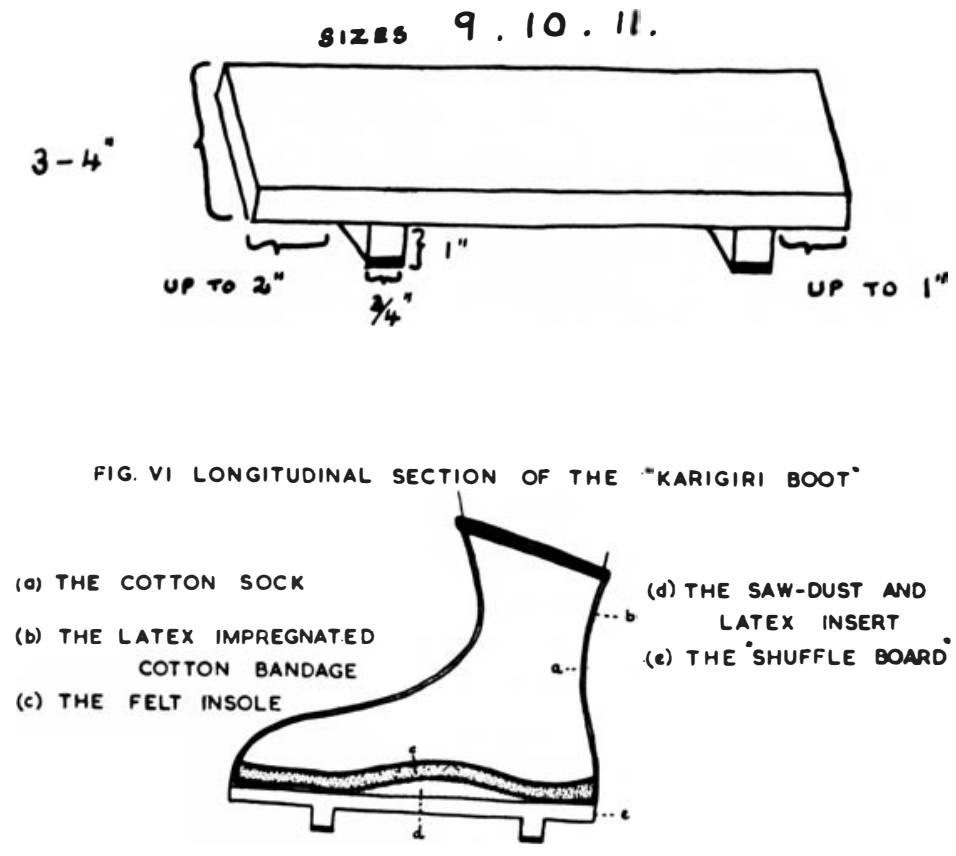

"KARIGIRI BOOT" 


\section{The Boot is made as follows:}

1. A cheap cotton sock of suitable length, or stockinette, is soaked in prevulcanised rubber latex. If the prevulcanised cannot be obtained then crude latex is almost as good but takes rather longer to dry. Both these substances can only be obtained in India under licence.

2. A piece of saddler's felt is cut sufficiently large to cover the whole sole of the foot and, after the application of a piece of dry gauze to the ulcer, the felt is applied to the sole (any cheap felt is suitable), provided that it is clean and approximately $! 2$ inch thick.

3. The latex impregnated sock is then drawn on to the foot over the felt, so as to hold the felt in place. The felt being inside the sock.

4. A handful of clean dry sawdust is then mixed with the latex to form a stiff paste.

5. A "Shuffle Board" is applied to the outside of the sock and the interstices between the board and the sock packed with the latex sawdust paste.

6. The whole is then bound firmly together by means of an open weave cotton bandage also soaked in the latex. The procedure is similar to the application of a skin tight plaster of paris cast to the foot and ankle, and the precautions should be observed. It is important to keep the foot at right angle to the leg during the application of the bandage and until the latex is reasonably dry, and to rub the boot to expel all the air from between the bandages during their application.

The boot may extend only to the ankle, or it may easily be extended up the leg to the knee. Both the cotton sock, or stockinette, and the bandages must be thoroughly soaked in the latex so that every thread is coated with rubber, but they should not be dripping wet. The easiest way to achieve this is to pour latex into an open dish to a depth of about one inch and then kneed the latex into the sock as a baker kneads water into his dough. The bandage should be rolled up simultaneously in the latex, again kneading the latex into the bandages as it is rolled. It is not sufficient to stand or even squeeze the rolled up bandage in the latex. Additional amounts of latex may be added to the dish as necessary. Two 3 in. $\times 108$ in. bandages are sufficient for a boot of average size, more will be for large feet or the long boot.

\section{ThE "Shuffle BoARD"}

This is a plain piece of board, box boarding is quite suitable, 3-4 inches broad and long enough to extend beyond the heel and toes, sizes 9, 10 and 11 inches will cover the majority of patients. Fixed to the under surface of the board are two wooden bars, each 
3 inches broad and 3 inches deep, shod with narrow strips of tyresole rubber. The rear bar should be 1 inch from the back and the front bar approx. 1! inches from the front.

The best position for the enterior bar, its optimal depth and its relationship to the metatarsal heads is still not finally settled. If the bar is at or behind the metatarsal heads then the foot can roll around the bar and at or behind the metatarsal heads and the gait will simulate the normal (Figure 7).

The main advantage of bringing the bar as far forward as the metatarsal heads is that a low bar is then sufficient to give an adequate take-off angle, whereas if the bar is near the centre of the board a very high bar is needed if an adequate angle is to be achieved (Figures 7 and 8). A high bar is unsightly and makes the gait unbalanced and unstable. It will be recalled from the section on etiology of ulcers that the normal take-off angle at the metatarsal heads may be up to 40 degrees, but anything over 30 degrees will enable the patient to walk in reasonable comfort and at a good pace, in these boots. If a single bar is used which is too low or not forward enough, then the foot is forced to pivot about the anterior end of the board and this result is excessive strain on the instep and probably on the
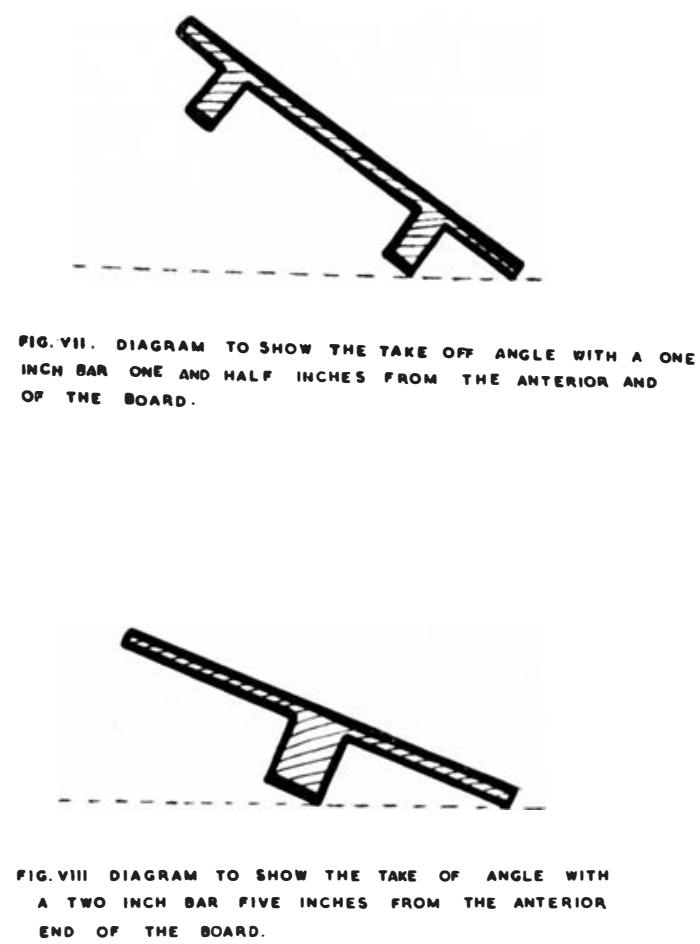


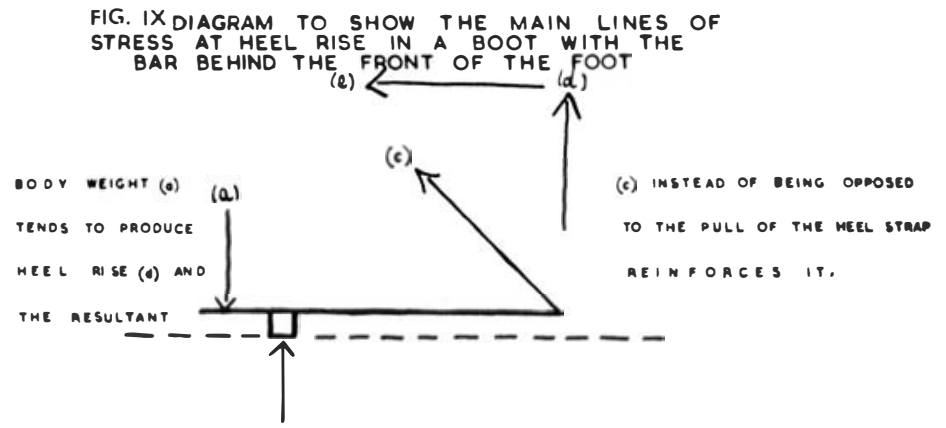

(b)

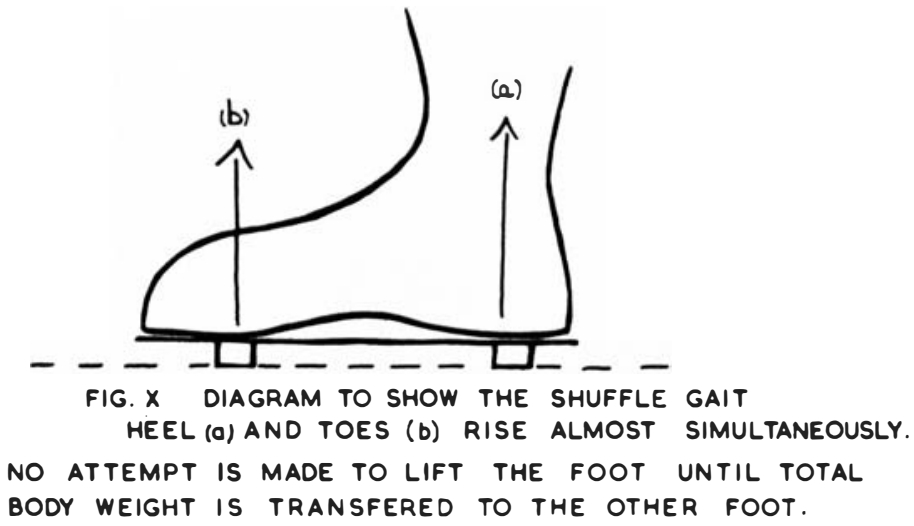

metatarsal heads also (Figure 9). Similarly if the anterior bar is placed in front of the fore then in the attempt to walk normally very great stress is thrown on to the heel-strap (Figure 9). Some patients persist in the attempt and succeed in cultivating a normal looking gait but at the expense of very much strain in the portion of the boot which keeps the heel in place on the shuffle board. Other patients adopt a shuffle walk in which no attempt is made to lift the foot until total body weight is transmitted to the other leg (Figure 10). The foot is lifted almost vertically upwards at take off, carried it forward, more or less parallel to the ground and then placed squarely on the ground at the beginning of the next phase of gait.

This gait probably completely eliminates thrusts at the metatarsal heads but it is ungainly and tiring. Our patients have done uniformly well in these boots whatever type of gait they have adopted. 


\section{Acknowledgements}

My grateful thanks for help and guidance to my teachers Dr. Paul Brand and Dr. E. W. Price.

\section{References}

1. Barnett, C. H. (1956) Lancet 2. 617.

2. BRAND P. W. (1959).

3. Clawson, D. K. and Seddon H. S. (1960) Journal of bone and joint-surgery45. 213.

4. Drisebach, J. (1959) "Leprosy in Theory and Practice" Edited by Cochrane R. G., John Wright and Son Ltd., Bristol.

5. FritsCHI, E P. and BRANI P. W. (1959) Internat J. Leprosy 25:1.

6. HameriJKx, F.(1959) Report on the activities and the Leprosy Control Campaign at the Belgian Leprosy Centre, Polambakkam.

7. Hicks, J. H. (1954) Brit. J. of Anstamy 88. 25.

8. Kulowski. J. and Porlman. R. (1936) Arch. Surg. 32. 1.

9. JoB, C. K. (1960) Personal communication.

10. Napier, J. R. (1957( J. Physiotherapy 43. 65.

11. Orr, H. W. (1928) American J. Surg. 4. 465.

12. Price, E. W. (1959) Leprosy Review. 30. 242.

13. Price, E. W. (1960) Leprosy Review. 31.97 and 159.

14. Truets, S. (1944) "Principles and Practices of War Surgery. 2nd. Edition. RaO, B. R. H. RaO. P. S. S. and Klontz. C. E. (1959) "General Health and Nurtition. Status Survey of the rural Population in Pennathur". Ind. J. of Med. Sc. 13. and 210. 